\title{
IS LIBERALISM COMMITTED TO ITS OWN DEMISE?
}

\author{
Hrishikesh Joshi
}

\begin{abstract}
RE IMmigration RESTRICTIONS compatible with liberalism? Recently, Christopher Freiman and Javier Hidalgo have argued that immigration restrictions conflict with the core commitments of liberalism. ${ }^{1}$ A society with immigration restrictions in place may well be optimal in some desired respects, but it is not liberal, they argue. So if you care about liberalism more deeply than you care about immigration restrictions, you should give up on restrictionism. You cannot hold on to both. I argue here that many restrictions on contractual, economic, and associational liberties seem to be justified by considerations other than liberty - thus the (undischarged) task for Freiman and Hidalgo is to tell us why such restrictions are justified but immigration restrictions are not. Moreover, even if this worry can be addressed, I argue, liberalism is not committed to its own demise in scenarios where there exist large enough numbers of would-be immigrants who accept and endorse illiberal norms in a way that is sufficiently resistant to change. Such a commitment requires thinking of border coercion as violating an absolute deontological constraint. This, I contend, is implausible.
\end{abstract}

\section{FREIMAN AND HIDALGO'S ARGUMENT}

The argument proceeds as follows. Immigration restrictions involve restricting people's basic liberties. Most fundamentally, they involve restrictions on freedom of movement, which is an important component of basic liberties like freedom of association and freedom of occupation. Primarily this affects would-be migrants. When a would-be migrant is stopped from relocating to another country by threat of coercive force at the border or at the airport, they are thereby forbidden to associate with employers, current and future friends and relatives, etc. In addition, they are stopped from pursuing certain occupational prospects. Immigration restrictions also curtail the freedoms of citizens. Most important-

1 Freiman and Hidalgo, "Liberalism or Immigration Restrictions, but Not Both.” 
ly, they prevent people from associating with would-be migrants. If you would like to hire somebody who happens to be a citizen of a different country but are unable to procure a work visa for that person, your freedom of association is thereby restricted. The same points hold for friends and relatives whom you would like to associate with on a regular basis in person.

Now, according to liberalism, Freiman and Hidalgo argue, only liberty-based reasons can be adequate for restricting liberty. The state may thus interfere with your freedom of occupation when it comes to your choosing to be a hitman. This is because being a hitman interferes with the basic liberties of others. However, the state may not interfere with your basic liberties for economic or cultural reasons. Thus it may not interfere with your decision to become a painter because you would increase the GDP by a greater amount were you to become something else. Likewise, it may not interfere with your professing Buddhism or teaching Nietzsche if doing so would alter the nation's culture in the long run. Or suppose that Buddhists are having more children on average than non-Buddhists and this is bound to change the culture of the country in the long run. This is not sufficient grounds for the state to interfere with the reproductive liberty of Buddhists within its territory. Of course, such liberty-restricting measures may conceivably arise within a democratic context—-the current majority may favor them. Even if they are democratically selected, however, they are not liberal. They conflict with liberalism.

Nevertheless, the authors note, the reasons given in favor of immigration restrictions usually appeal to economic or cultural considerations. David Miller, for example, argues that a country's citizens have a right to collective self-determination, and they may thus exclude foreigners so as to promote cultural continuity. ${ }^{2}$ Others, for example Stephen Macedo, argue that adverse economic effects on the worst-off members of society are a good reason to limit immigration. ${ }^{3}$ Yet, if cultural or economic considerations are not good enough to restrict basic liberty, and if freedom of movement constitutes or is an essential precondition for a basic liberty or liberties, then such arguments proceed from premises that are not consistent with liberalism. In other words, since the offered reasons in favor of immigration restrictions are not liberty-based, liberalism is not consistent with restricting immigration for those reasons.

2 Miller, "Immigration: The Case for Limits" and "Is There a Human Right to Immigrate?"

3 Macedo, "The Moral Dilemma of U.S. Immigration Policy" and "When and Why Should Liberal Democracies Restrict Immigration?” 


\section{ONLY LIBERTY-BASED REASONS?}

While Freiman and Hidalgo take freedom of movement as an important liberty that liberal states protect, they do not specify what it amounts to. Presumably they think a detailed account is unnecessary-there is certainly a sense in which a resident of New York is free to move to Los Angeles in a way that she is not free to move to Vancouver (she will need to go through a visa process). They might be operating under the assumption that this intuitive distinction is all that is required for their argumentative purposes.

The problem is that even liberal states restrict freedom of movement within their borders in important ways. I am not free to enter your property or stay there without your permission. Similarly, the government may decide to disallow the general public from entering a particular national park during caribou-mating season. Yet, intuitively, these types of restrictions are manifestly compatible with liberalism. The question that arises then is: on what conception of freedom of movement will it turn out that immigration restrictions violate liberty but property laws and national parks do not? Further, notice that some people enjoy the freedom of movement to specific areas within liberal polities that others do not. You do not need permission to enter your property, but I do. Rangers or maintenance staff might be allowed to enter the national park during caribou-mating season. So, why are these distinctions unproblematic while the distinction between citizens and legal permanent residents on the one hand and "nonresident aliens" on the other is problematic?

Moreover, it is not obvious that all restrictions on liberty need to have liberty-based reasons according to liberalism. Cigarette taxes restrict your liberty. But the most compelling justifications for such taxes are paternalistic or economic. Occupational licensing laws restrict your freedom of occupation, but the justification for them is the provision of a public good-namely the ability of individuals to trust the medical, legal, and other systems - and to ensure safety standards. Zoning laws restrict your liberty, and the justifications for them often appeal to economic, distributional, and aesthetic considerations. A minimum wage law of $\$ x$ per hour limits your freedom of association by forbidding you to hire someone at a rate of less than $\$ x$ per hour; in this way, it also restricts would-be employees' freedoms of association and occupation. Similar points can be made about a host of other things. Importantly however, a view according to which liberalism commits us to getting rid of these restrictions is extremely revisionary; hence, relying on such a view would render the authors' argument much less interesting than it appears at first glance. While these are all restrictions on liberty in some sense, one may argue that such measures are not suf- 
ficiently drastic to count as violations of basic liberties, but on the other hand, immigration restrictions are sufficiently drastic. The task for Freiman and Hidalgo, then, will be to give a characterization of what counts as a violation of basic liberties that is not merely an ad hoc construction to support their view. This is brought out, for example, by the fact that minimum-wage laws restrict your freedoms of occupation and association. Freiman and Hidalgo may say that you still enjoy adequate freedom of occupation even if you cannot work for somebody willing to only pay less than $\$ x$ per hour. In other words, minimum-wage laws do not interfere with your freedom of occupation simpliciter. Rather, they merely impose certain conditions on employment. But notice that the case is similar with immigration-immigration restrictions do not typically restrict anybody's freedom of movement simpliciter. Rather, they merely impose the condition that movement into a country's territory must be accompanied by the appropriate visa. Indeed, would-be immigrants are (typically) free to move about within their origin countries as well as any other country that allows them to enter and stay within its territory. ${ }^{4}$

\section{IS LIBERALISM COMMITTED TO SUICIDE?}

In what follows, I will assume these challenges can be met. Even so, I argue, liberalism can be consistent with (and may even require) immigration restrictions, because there can be strong, forward-looking, liberty-based reasons for some such restrictions.

Consider the two hypothetical countries below:

LIBERAL DEMOCRACY is a country where people enjoy and support liberal freedoms. There are robust protections for freedom of speech and press.

4 A further problem for Freiman and Hidalgo is that one of the most popular conceptions of basic liberties - the Rawlsian idea-will be of little help in making their case. According to leading Rawls scholar Samuel Freeman, the Rawlsian conception of basic liberties is that they are "an essential social condition for the adequate development and full exercise of the two powers of moral personality over a complete life" (Freeman, Rawls, 55). Of the two moral powers, the first is the capacity to "have a rational conception of the good-the power to form, revise, and to rationally pursue a coherent conception of values, as based in a view of what gives life and its pursuits their meaning." The second is the capacity to "understand, apply, and cooperate with others on terms of cooperation that are fair" (Freeman, Rawls, 54). The problem with using this view of the basic liberties is that freedom of movement across national borders is typically not needed to develop these powers. You can develop these powers while living in the United States even if you are not free to move to Canada or Brazil or India without meeting residency visa requirements. (This point is developed in Brennan (Against Democracy) to argue that political liberties are not basic liberties.) 
Sexual acts between consenting adults of the same sex are not criminalized. There are no public dress codes (with exceptions for nudity). There is robust freedom of religion, and so on. The country has a population of ten million.

THEOCRACY is a democratic country where the overwhelming majority of people do not support liberal freedoms. Blasphemy against the majority religion is punishable by execution. Sexual acts between consenting adults of the same sex are criminalized. Men and women have different laws applicable to them, and the latter are second-class citizens in many ways. Religious minorities are de facto persecuted, and defection from the majority religion is officially banned. The country has a population of two hundred million.

Suppose that LIBERAL DEMOCRACY has a GDP per capita that is twenty times higher than that of THEOCRACY, so that many residents of the latter want to move to the former for economic reasons. Economists and social scientists estimate that roughly half the population of THEOCRACY would move to LIBERAL DEMOCRACY within five years if the latter eliminated visa restrictions.

Now, it is a thoroughly empirical question whether, if people from THEOCRACY move to LIBERAL DEMOCRACY in such large numbers, they will keep or change their illiberal norms and beliefs. Let us suppose that norms and cultural beliefs are sticky, and that immigrant communities within LIBERAL DEMOCRACY tend to form homogenous pockets that facilitate and promote the maintenance of antecedent cultural norms. Hence, whether or not immigrants from THEOCRACY to LIBERAL DEMOCRACY will adopt liberal norms and beliefs will partially depend on the numbers that are accepted and the time period over which they are accepted; let us suppose that if one hundred million people were to move within five years, their norms will largely remain intact.

Notice that the question here is not merely one of culture. The difference in norms that is relevant here is not merely the difference between language, food, greeting methods, types of holiday celebrations, etc. Rather the difference is between liberal norms and beliefs on the one hand, and illiberal ones on the other.

Let us suppose that if such a movement occurs, various kinds of informal social institutions and norms will shift markedly in the illiberal direction. There will be a "chilling effect" on things like speech, dress, movement, and association. Given the huge population shift, the original residents of LIBERAL DEMOCRACY will become wary of professing atheism or insulting the religion of THEOCRA$\mathrm{Cr}$. Women might have to change their public behavior in order to avoid severe 
harassment. LGBT folk will be pushed to be less open about their sexuality. And so on.

All this can happen without the new immigrants having voting rights. If they are granted voting rights, then given that they outnumber the original population ten to one, they will vote for politicians who will push for laws that resemble the laws of THEOCRACY. Soon enough, Liberal DEMOCRACY will no longer be a liberal democracy.

This is a hypothetical scenario, but an important test case for Freiman and Hidalgo's view. Since such a scenario cannot be ruled out a priori, and since there are possible worlds in which it is true, we can ask what the demands of liberalism are in this scenario. Is liberalism bound to commit suicide in such cases? That is, does liberalism commit us to policies that would, under certain circumstances, foreseeably eliminate its existence?

Such a consequence seems implausible for two chief reasons. For one, it seems that liberal societies are intrinsically valuable given the relationships between coresidents that they embody. Liberal societies are also instrumentally valuable insofar as they promote certain kinds of cultural and scientific achievements, given the ability of individuals to speak, think, and associate in a relatively free way. They also stand as a model for other, less liberal societies to emulate.

Second, there seem to be liberty-based reasons to restrict the freedom of movement of people from THEOCRACY seeking to migrate to LIBERAL DEMOCRACY - namely that doing so will preserve the liberties that citizens of LIBERAL DEMOCRACY enjoy. The aim of maintaining and promoting the existence of liberal polities is a liberty-based aim.

Freiman and Hidalgo may worry that the kind of reasoning sketched here will also motivate other restrictions on liberty that are intuitively at odds with liberalism. Thus suppose that, within LIBERAL DEMOCRACY, there exists an illiberal minority that is growing in influence and number. Would it be consistent with liberalism for the state to restrict their freedoms of speech and association, or seek to deport this group to a country that will accept them in exchange for aid, for example?

There are two main things to be said in response here. First, some measures are greater violations of individual liberty and autonomy than others, and thus require a greater burden of justification. Sin taxes are restrictions on liberty but stand in need of less justification than restrictions on freedom of speech, for example. Likewise, while granting that border controls involve restricting wouldbe migrants' liberty, such controls stand in need of less justification than moves to deport long-term residents. Second, some restrictions on liberty, even if they are to be tolerated in principle, are more prone to practical difficulties than oth- 
ers. Controlling immigration has less potential for institutional slippery slopes than controlling the speech of even extremely illiberal elements. Restrictions on speech, in other words, are ripe for abuse in a way that legal restrictions on immigration are not. ${ }^{5}$

Freiman and Hidalgo might bite the bullet here and contend that even in the hypothetical situation described above, it is illiberal for LIBERAL DEMOCRACY to seek to impose immigration restrictions. For, they may argue, the demands of liberalism take the form of absolute deontological constraints. Therefore, even if open borders between the two countries will foreseeably end the existence of liberal democracy, so be it. Let justice be done though the heavens fall, as the saying goes.

The problem is that plausible absolute deontological prohibitions are very rare (if they exist at all). ${ }^{6}$ Hence, many deontological theorists are not absolutists. W.D. Ross's theory, for example, allows for obligations (prima facie duties) to be outweighed by sufficiently weighty considerations. ${ }^{7}$ As an illustration, consider the commonly acknowledged deontological prohibition against breaking promises. This might allow us to say that if on the day of a promised lunch, even if I calculate that my staying home would result in +11 utils, whereas my fulfilling the promise would result in +10 utils, I may not break the promise. Yet, if breaking a promise is the only way to stop a murder, it is permissible, and depending on the circumstance even obligatory, to break the promise. ${ }^{8}$

Now, it is highly implausible that restrictions on the freedom to move across international borders are barred by absolute deontological prohibitions. Indeed, if stopping one person at the border who does not have the required visa is the only way to stop a nuclear catastrophe from killing one million people, the border stopping is the right thing to do.

But perhaps, more weakly and plausibly, there is a prima facie duty not to restrict such freedoms. The task for Freiman and Hidalgo, then, is to argue that the foreseeable end of liberal democracy in the hypothetical scenario is not an evil weighty enough to warrant restricting the freedom of movement for those

5 The challenges I have in mind include, but are not limited to, the sorts of worries raised famously in Mill, On Liberty and Other Essays.

6 Immanuel Kant famously thought that you should not lie even to prevent a murder, but I take it that most modern ethicists believe this is quite implausible. However, there is some dispute as to whether he is committed to this; see Korsgaard, "The Right to Lie."

7 Ross, The Right and the Good.

8 A further issue is that absolute prohibitions can lead to a proliferation of ethical dilemmas. If there is an absolute deontological prohibition against breaking promises, but the only way you can fulfill promise A is by breaking promise B, what should you do? 
in THEOCRACY. Given the intrinsic and instrumental value of liberal societies mentioned above, it is not obvious that they can succeed.

Now, in the hypothetical scenario, I have assumed that LIBERAL DEMOCRACY will definitely come to resemble THEOCRACY in its norms and institutions. But what if, given the best evidence, this is not a certainty, but a mere (sizable) risk? While a consequentialist would just perform a cost-benefit analysis, does weakening the assumption pose a special problem for someone who accepts deontological restrictions against border coercion? Plausibly not: for deontological theories can take risks into account when determining whether some prima facie duty is overridden. Indeed, many freedoms are rightly restricted because of the risks involved with respect to the liberties of others-even if the bad outcome is not certain to come about. For example, consider the restrictions on drunk driving, entering airports, pollution, gun ownership, etc.

If this section's argument succeeds, then the question of whether liberalism is committed to open borders turns on the empirical question of whether the actual world sufficiently resembles the hypothetical scenario. I do not wish to delve into that empirical question here. However, if I am right, the connection between the core commitments of liberalism and immigration policy hinge on empirical issues to a much greater degree than the authors appreciate. ${ }^{9}$

University of Michigan, Ann Arbor joshih@umich.edu

\section{REFERENCES}

Brennan, Jason. Against Democracy. Princeton: Princeton University Press, 2016. Freeman, Samuel. Rawls. London: Routledge Press, 2007.

Freiman, Christopher, and Javier Hidalgo. "Liberalism or Immigration Restrictions, but Not Both." Journal of Ethics and Social Philosophy 10, no. 2 (May 2016).

Korsgaard, Christine. “The Right to Lie: Kant on Dealing with Evil.” Philosophy and Public Affairs 15, no. 4 (Autumn 1986): 325-49.

Macedo, Stephen. "The Moral Dilemma of U.S. Immigration Policy: Open Borders Versus Social Justice?" In Debating Immigration, edited by Carol M. Swain, 63-81. Cambridge: Cambridge University Press, 2007. . "When and Why Should Liberal Democracies Restrict Immigration?"

9 Thanks to Jonathan Anomaly and Daniel Jacobson for extensive comments on earlier drafts, and to the editors and an anonymous reviewer at the Journal of Ethics and Social Philosophy. 
In Citizenship, Borders, and Human Needs, edited by Rogers M. Smith, 301-23. Philadelphia: University of Pennsylvania Press, 2011.

Mill, John Stuart. On Liberty and Other Essays. Edited by John Gray. Oxford: Oxford University Press, 1991.

Miller, David. "Immigration: The Case for Limits." In Contemporary Debates in Applied Ethics, edited by Andrew I. Cohen and Christopher Heath Wellman, 193-206. Malden, MA: Blackwell, 2005.

."Is There a Human Right to Immigrate?" In Migration in Political Theory: The Ethics of Movement and Membership, edited by Sarah Fine and Lea Ypi, 11-31. Oxford: Oxford University Press, 2016.

Ross, W.D. The Right and the Good. Oxford: Oxford University Press, 1930. 